Dialectic Volume I, Issue I: Position Paper

\title{
Defining Design Facilitation: Exploring and Advocating for New, Strategic Leadership Roles for Designers and What These Mean for the Future of Design Education
}

PAMELA NAPIER ${ }^{1}$ AND TERRI WADA ${ }^{2}$ (EDITED BY MICHAEL R. GIBSON) ${ }^{3}$

1. Indiana University Herron School of Art and Design (IUPUI), Indianapolis, Indiana, USA; Principal in Collabo Creative, Indianapolis, IN, USA

2. Indiana University Herron School of Art and Design (IUPUI), Indianapolis, Indiana, USA; Principal in Collabo Creative, Indianapolis, IN, USA.

3 The University of North Texas, Denton, Texas, USA; Producer and Co-Editor, Dialectic, a scholarly journal of thought leadership, education and practice in the discipline of visual communication design published by the AIGA Design Educators Community (DEC) and Michigan Publishing.

SUGGESTED CITATION: Napier, P. \& Wada, T. "Defining Design Facilitation: Exploring New, Strategy Leadership Roles for Designers and What These Mean for the Future of Design Education." Edited by Gibson, M.R. Dialectic 1.1 (2016): 154-178. DOI: http://dx.doi.org/10.3998/dialectic.14932326.0001.110 


\title{
Defining Design Facilitation:
}

\author{
Exploring and Advocating for New, Strategic Leadership Roles \\ for Designers and What These Mean for the Future of Design \\ Education
}

PAMELA NAPIER \& TERRI WADA

(EDITED BY MICHAEL R. GIBSON)

\section{Examining current prevalent trends in design practice and education}

Over the past decade or so, design as a professional and academic discipline has seen much momentum and growth in interest from areas of both study and practice outside design. Over the course of the last decade, the buzz around design thinking as a transferable "method of creative action" "for developing and implementing innovative ideas has grown into broad assortment of executive education offerings and workshops. Professionals in arenas such as healthcare, business management and education have made concerted efforts to adopt designerly approaches ${ }^{2}$ to identifying, framing, operationalizing, and,

1

Faste, R., Roth, B. \& Wilde, D.J. "Integrating Creativity into the Mechanical Engineering Curriculum." In ASME Resource Guide to Innovation in Engineering Design, edited by C. A. Fisher. New York, New York, USA: American Society of Mechanical Engineers, 1993.

2

Cross, N. "Designerly Ways of Knowing." Design Studies, 3.4 (1982): pgs. 221-227. eventually, assessing the efficacy of new initiatives. Design processes and socalled 'design thinking' have been recognized widely as viable means to fuel innovative practices, and, in some cases, the invention of new ways of doing, making, distributing and communicating.

Additionally, there has been both an emergence and surge in university-level design education programs in many parts of the world offering degrees in design management, design strategy and design leadership. Much of this growth can be attributed to the recognition design has gained for being a "game changer" in the industrial, economic and social realms. As a result of this growth, contemporary designers are now being sought after as project partners and researchers by academics and professionals working in and 


\section{3}

Cary, J. "What Is Design If Not Human-Centered?" Stanford SOCIAL INNOVATION Review, 25 June 2013. Online. Available at: https://ssir. org/articles/entry/what_is_design_ if_not_human_centered (Accessed 4 December, 2016).

\section{4}

Buchanan, R. "Human dignity and human rights: Thoughts on the principles of human-centered design." Design Issues, 17.3 (2001): pgs. 35-39; Norman, D. “Human-centered design considered harmful." Interactions, 12.4 (2005): pgs. 14-19. 5

Sanders, E. \& Stappers, P. “Cocreation and the new landscapes of design." CoDesign, 4.1 (2008): pgs. $5-18$.

6

Martin, R. The Design of Business: Why Design Thinking is the Next Competitive Advantage. Cambridge, MA, USA: Harvard Business Press, 2009: pgs. 57-78.

\section{7}

Fraser, H. M. A. "Designing Business: New Models for Success." In Design Thinking: Integrating Innovation, Customer Experience, and Brand Value, edited by T. Lockwood, pgs. 35-46. New York, NY, USA: Allworth Press, 2009. across areas as diverse as healthcare, education, crime prevention, business instantiation and development, and urban and rural planning and revitalization. Designers are sought after because of their abilities to bring unique knowledge rooted in their understandings of creative processes to complex problems that require socio-cultural reframing, the empathetic inclusion of users in decision-making processes, and the invention of new processes and procedures for making and doing.

People-centered design has recently become synonymous with human-centered design, and has been promoted by the likes of IDEO and the d.school at Stanford University. ${ }^{3}$ This advocacy builds upon earlier scholarship undertaken by Richard Buchanan and Donald Norman, ${ }^{4}$ and continues to be examined and expanded in both design practice and design education. Despite its similarities with other, more established, design approaches - for example, "user-centered design"-people-centered design, as described in this paper, not only places potential users and stakeholders at the center of the design process, but additionally calls for and places value upon their active inclusion or participation in the identification and framing of problems, or problematic situations, within the particular communities that they live and work within, or that they routinely traverse. These communities can be actual, physical places, such as schools, healthcare facilities and neighborhoods, or virtual environments, such as online retail and news outlets, social media networks and data-delivery websites that provide information about the weather, sports and the financial markets. This approach also calls for users and stakeholders to be involved in the development and implementation of positive, efficacious changes that will or could affect their lives and livelihoods. This shift in approach to formulating and operating design processes that call for user or stakeholder participation during their so-called "front ends" changes the more established notion of "designers designing for users to designers designing with users." ${ }^{5}$

Involving people who possess different areas of expertise in thinking and decision-making that yield outcomes to design processes that are demonstrably more effective, or more desirable, or more efficient (or some combination of these) requires what has come to be known in some professional and educational design arenas as "design facilitation." This term describes a process that has been shown to aid and abet innovative practices within and between organizations and organizational cultures, and, in some cases, to help them gain competitive advantage in particular markets. ${ }^{67}$ Design facilitation shifts the primary intent of the design process from yielding an artifact or set 
of artifacts - a branding system, a graphical user interface, a piece of furniture, a retail space - to yielding outcomes that identify needs, clarify goals or that help diversely populated groups decide where a given initiative should be started, what parameters should guide its evolution, and what should constitute “next steps.” Effective design facilitators, especially those involved in design education, know that teaching and gaining understanding of these processes is often as crucial to what can be defined as "a successful outcome" as is achieving a hard, artifact-based deliverable like a logo, or a piece of furniture, or a user interface.

The trend toward design facilitation, and the need for broadly inclusive user participation in people-centered design projects has initiated many new and unique challenges for emerging designers. Today, designers who wish to sustain careers in many professional design arenas are being asked to construct and cultivate knowledge and experience with participatory design research approaches and methods to engage users empathetically, which involves attempting to deeply and broadly understand their experiences and socially, economically and politically contextualized viewpoints. This type of designing allows designers and their collaborators to create more desirable and useful means for people to effectively confront the challenges inherent in their everyday lives. These challenges can involve activities as diverse as shopping for groceries for people with dietary restrictions, engaging in family financial planning and the need to effectively juggle the demands of work, family and personal health for people who live from paycheck-to-paycheck. The complexity of the daily challenges individuals in contemporary societies must meet to live productive and - hopefully — meaningful lives is driving a need for emerging designers to learn to serve as facilitators of people-centered, participatory design research that effectively guides design decision-making processes.

\section{A justification for and selevance of design facilitation}

\section{A description of the current landscape in design education and practice}

The effective facilitation of human activity and aspiration is not a new concept or practice in design: its roots can be traced back to the Wiener Werkstätte, The Bauhaus, The Ulm School of Design, and the work of the so-called "design meth-

Bayazit, N. “Investigating Design: A Review of Forty Years of Design Research." Design Issues, 20.1 (2004): pgs 16-29. odologists" of the 1960 s. $^{8}$ Within the last 20 years, numerous books and white papers have been published around the topic of facilitation, or enabling significant positive change, and international associations and institutions have been created to critically examine and support scholarship to inform it. The 
9

Brewster, B., Dowse, E., Hogan,

D., Wilkinson, M. \& Woosley, B. "History [of INIFAC]," INIFAC, The International Institute for Facilitation, 28 September, 2006. Online. Available at: http://inifac.org/ about-inifac.htm (Accessed 29 November 2016).

10

+Acumen. "Design kit: Facilitator's guide to introducing human-centered design." +Acumen. Online. Available at: http://plusacumen.org/courses/ design-kit-facilitators-guide-to-introducing-human-centered-design/ (Accessed 12 0ctober, 2016).
International Association of Facilitators (IAF), was formed in 1994, has members in over 65 countries, and provides accreditation, certification and conferences worldwide. The International Institute for Facilitation (INIFAC) was created in 2003 “....when five facilitators came together to develop a certification program at the masters' level [and] developed a draft of competencies and sub-competencies specifically designed to define the knowledge and skills needed to achieve outstanding facilitated sessions." ${ }^{9}$ Much of what the IAF and INIFAC exist and have existed to accomplish and promote parallels the need in contemporary design education to teach emerging designers to plan and operate at least portions of their careers as critical agents for positive social, technological, economic and political change.

Over the course of the last decade, the concept of design facilitation has been gaining traction. While the term itself is relatively new, hundreds of companies and organizations across the (mostly) developed world have begun offering workshops and training programs specifically designed to help people cultivate the ability to utilize design thinking as a means to engage in problem identification, framing and solving processes. In this context, design thinking refers to the process of developing, constructing, testing and assessing prototypical ways of doing, making or creating that yield innovative outcomes and, sometimes, inventive solutions to problems. One example of this is The Design Thinkers Academy (http://www.designthinkersacademy.com), which operates a series of service design thinking facilitation workshops in several countries in Europe. In the U.S., organizations like the Next Design (NextD) Leadership Institute - created and operated in New York City by Humantific co-founders Elizabeth Pastor and Garry K. Vanpatter - have offered innovation skill-building programs that teach skills specifically around facilitation. The recently founded "learn-by-doing community" known as The Design Gym in New York City offers classes and workshops with titles like "Improv for Design Thinking," "Facilitation Bootcamps," and “Facilitation Practice Labs." And, more recently, IDEO. org and +Acumen teamed up to offer "The Facilitator's Guide to Introducing Human-Centered Design," 10 a step-by-step guide to help "introduce new learners to this creative approach to problem solving." "11 AIGA (the American Institute for Graphic Arts, and the sponsor of the journal within which this article has been published) also began offering a series of Facilitation: by Design workshops at select locations across the U.S. in 2012, and which have since proven to sell out rapidly. These seminars provide training that "successfully leads diverse groups of stakeholders through design-thinking exercises and [helps them to] develop 
solutions to complex problems." 12 The popularity of these types of workshops in the U.S., western Europe and Australasia has seen a steady increase since the early 2000 s. So has the variety of open-source tools designed to facilitate design thinking, design-led planning and management strategies, and design-led innovation. Viewed broadly, these are indicative of the recognition of the expanding roles designers now play as thought leaders, innovators and change managers across an increasing array of disciplinary boundaries, and the need (and desire) to have emerging designers develop new sets of skills that will allow them to successfully operate within these growing areas of design.

\section{Examining the expansion of roles and the emergence of new skill sets for future designers}

The logistical and intellectual complexities inherent in practicing people-centered design require the active, broadly inclusive participation and, at times, collaboration between designers, users and stakeholders throughout the design process. The processes (note the plurality of this term) are cyclic, and endeavor to overcome a wide variety of biases and assumptions that designers or design teams and their project partners may have about how given factors, conditions and the people involved in a given situation might affect each other. In order to practice people-centered design and participatory design research, designers must be able to effectively facilitate the perceptions and pursuant actions of others through a design process that is geared to yield new ways of thinking and doing, rather than being limited to yielding only artifacts or systems of artifacts. They must be able to develop, plan and facilitate activities that enable and empower people to collaboratively express, make, assess and reflect upon their progress in ways that allow them to collectively identify, frame and at least suggest improvements to problematic situations (or "solve the prob-

12

AIGA. "Register for Facilitation: by Design workshops." AIGA. Online. Available at: http://www.aiga.org/ facilitation-by-design/ (Accessed 9 July, 2015).

13

Norman, D. "Why design education must change." Core 77, 10 November 2010. Online. Available at: http:// www. core77.com/posts/17993/why-design-education-must-change-17993 (Accessed November 4, 2016). lems" inherent within these situations outright).

Designers who aspire to serve as facilitators of research, or the ability to engage in the kinds of systemic investigations that yield knowledge (that then guide design actions), need to actually be taught how to do this appropriately and effectively by people who know how to do this themselves. Facilitating learning experiences that can help emerging designers cultivate the understandings necessary to frame appropriate theoretical frameworks and effective data gathering and processing methods is not an easy one, especially in the U.S., given that so many design educators have not been effectively educated to do this. ${ }^{13}$ 
14

Frascara, J. \& Winkler, D. “Jorge

Frascara and Dietmar Winkler on

Design Research." Design Research

Quarterly, 3.3 (2008): pgs. 5-6.

15

Ibid.

16

The authors have published another piece that describes these types of approaches to facilitating design and co-designing: Napier, P. \& Wada,

T. “Co-designing for Healthcare: visual designers as researchers and

facilitators." Visible Language, 49.1-2 (2015). Online. Available at: http://visiblelanguagejournal.com/ issue/161/article/961 (Accessed 2 December 2016). $16 a$

Dorst, K. \& Lawson, B. Design Expertise. New York, NY, USA: Architectural Press, (an imprint of Routledge, an imprint of Taylor $\delta$ Francis), 2009, pgs. 159-166.
Longtime North American design educator Jorge Frascara supports the need for design educators - particularly those working in graphic design - to endeavor to re-frame what they do and what they teach in ways that catalyze positive social, economic and public policy change: "There is a distinct difference between graphic design as useless styling and communication design as a way of supporting a social discourse between diverse segments of society." ${ }^{14}$ He further advocates for contemporary design programs to:

- “develop efficient and supporting communication tools to promote solutions for problems;"

- "offer federal, state, and local governments their services to facilitate local, regional, national, and international efforts for developing and disseminating innovative plans for achieving...goals within reasonable timeframes;

- facilitate the adoption of their plans." 15

Much of what of what Frascara is advocating for here has been advanced by those relatively few educators teaching and practicing design facilitation in the U.S., Canada and abroad over the course of the past decade.

Placing contemporary graphic (or visual communication or interaction) design students in learning situations that locates some portions of their learning experiences within these arenas can help ensure that they develop the ideological and practical tools necessary to facilitate design as a broadly transformative activity as their careers evolve. Too many students learn how to make, but not why, or why not, (to make), or how their making processes might help diverse communities address and resolve difficult social, economic, technological or public policy issues.

\section{Contextual Approaches and Methodology}

\section{A set of broadly informed questions to guide possible approaches}

In our research over the past few years - both as design educators and practitioners - we (the authors) have explored and tested several new approaches, tools and frameworks for teaching visual communication design students at both the graduate and undergraduate levels how to become effective design facilitators.

Our epistemological approach has been contextualized by the following research questions: 
a Our definition of "people-centered design processes" is adapted from Jorge

Frascara's chapter on the subject that appeared in a book he edited titled Design and the Social Sciences: Making Connections (Taylor \& Francis, 2002, p. 33). In order for designers to effectively engage in people-centered design, he contends that, "We have to stop thinking of design as the construction of graphics, products, services, systems and environments, and think about those as means for people to act, to realize their wishes and satisfy their needs. It is the needs and the wishes we have to serve; the objects of design must be seen only as means. This requires a better understanding of people, of society, and of the ecosystem, and calls for an interdisciplinary practice."

${ }^{\mathrm{b}}$ Participatory design, or co-design, emerged from ideas that originated in Scandanavia in the 1970s in and around the realms of software systems development. The idea that participants could cooperate with designers, researchers and developers

during the evolution of inventive and innovative processes was eventually adapted into healthcare, information technology, human + computer interaction design, architecture and urban design as the 1970 s gave way to the 1980 s and 1990s. For more

information about the origins of participatory design and co-design, the editors of Dialectic advise readers to reference the following scholarship:

"Co-designing for Society" by Deborah Szebeko and Lauren Tan (Szebeko, D. \& Tan, L. “Co-designing for soci-

ety." Australasian Medical Journal, 3.9 [2010]: pgs. 580-590); and "Co-creation and the new landscapes of design" by Elizabeth Sanders and Pieter Stappers (Sanders, E. \& Stappers, P. "Co-creation and the new landscapes of design." CoDesign 4.1 [2008]: pgs. 5-18.)
How does the changing role of visual communication designers (from more traditional "making" roles to "design facilitators" working to effectively implement people-centered design processes ${ }^{\text {a }}$ ) impact the curricular goals and experiences of visual communication design students, at both graduate and undergraduate levels?

How might understanding shifts/advancements in our discipline and the current practice of design facilitation positively inform/impact curriculum? How might new frameworks and tools positively affect students' abilities to plan and execute facilitated participatory design sessions?

We have embarked on an ongoing process of research and practice in our quest to address these questions surrounding design facilitation. This has involved our attendance at design facilitation workshops, our working with various clients and partners as we engage in design facilitation, our testing and implementing new frameworks and approaches involving design facilitation in our design studio (as well as sharing those with educators in other institutions), and, ultimately, our public presentations on this topic, and our writing about these efforts in articles like this one. ${ }^{16}$

\section{Establishing a methodological foundation}

The work described in this piece is largely influenced by participatory action research, which is grounded in accounting for the experiences, reflections, and inclusive collaborations with others throughout the research and design process. This article is informed by both primary and secondary sources, and the author's own facilitations of participatory processes in classroom, workshop, and practice-based settings.

In our design practice, we have developed a process and methodology that focuses on the seminal axiom of participatory action research, or "co-design," which is to strive to design with people, rather than for them. ${ }^{\text {b }}$ Initially, our process is comprised of three main phases: Analysis, Synthesis and Evaluation. These have been recognized as being necessary to engage in "the highest-level design processes" - meaning that considerable experience accrued through extensive practice is necessary to make effective use of these types of processes - by Bryan Lawson and Kees Dorst in their book Design Expertise. ${ }^{16 a}$ Each of these iterative phases is further broken down as follows: Sensing current conditions, Understanding behaviors and experiences, Framing insights \& challenges, Ideating possible solutions, Iterating to test and refine, 
17

Unger, R. Willis, D. \& Nunally, B. Designing the Conversation: Techniques for Successful Facilitation. San Francisco, CA, USA: New Riders/ Peachpit, a division of Pearson Education, 2013 , p. 6 .

18

Thinkplace specializes in applying what they refer to as design thinking to a diverse array of complex, public sector challenges. More information about Thinkplace can be accessed online at http://www. thinkplaceglobal.com/\#page (Accessed November 25, 2016).

\section{9}

Sanders, L. \& Stappers, P. Convivial Toolbox: Generative Research for the Front End of Design. Amsterdam, The Netherlands: BIS Publishers, 2008. and Implementing for final production. Each of these phases are affected by the critical input of those who will be affected by our design decision-making, so that a diverse array of audience members and potential users are allowed to have some affect across the entire design process. The ultimate goal of utilizing these methods is to empower those who use them to effectively communicate their experiences (of use, and that involve cognition and behavior/action). These communications can then be used to help identify and frame core problems in and around specific situations, and, in so doing, help contribute to the creation of meaningful impact, positive change, and innovation within the scope of a given project.

\section{Examining means to effectively formulate and operate design facilitation}

There are numerous scholarly and more publicly accessible resources (literally dozens are available through the Design and Applied Arts Index alone) that exist generally around the topic of facilitation as it has affected or can affect design processes, but far fewer that examine why the particular skills and traits necessary to effectively engage in or support facilitation are necessary - and uniquely suited - to designers. There is also only a paucity of resources that, given specific sets of circumstances, identify what types of facilitation practices are most appropriate and when, and what specific skill sets, professional traits and domains of knowledge are of paramount importance to bring to bear within a given social, economic or public policy context.

Design facilitation is an emerging type of design process that is fast becoming a core competency of designers who find themselves needing to engage in people-centered, participatory approaches to meet the intertwined demands of clients and the needs of particular groups of users and audiences. In their writings on design facilitation, Unger, Nunnally and Willis offer, "It takes skill and practice to be able to facilitate [on behalf of] people, and facilitation is truly the foundation of an effective design practice." ${ }^{17}$ Education and training that might help emerging designers build this core competency has been largely unavailable in university-level design curricula in the U.S. until fairly recently (again, there simply aren't enough American design educators who have acquired the expertise in this area to teach it well). John Body, Nina Terrey and Leslie Tergas of the Australia-(and New Zealand-, Kenya-, and Singapore) based strategic design consultancy ThinkPlace ${ }^{18}$ describe the increasing complexity of formulating and operating design applications within the context of 


\section{People-Centered Design Approach}

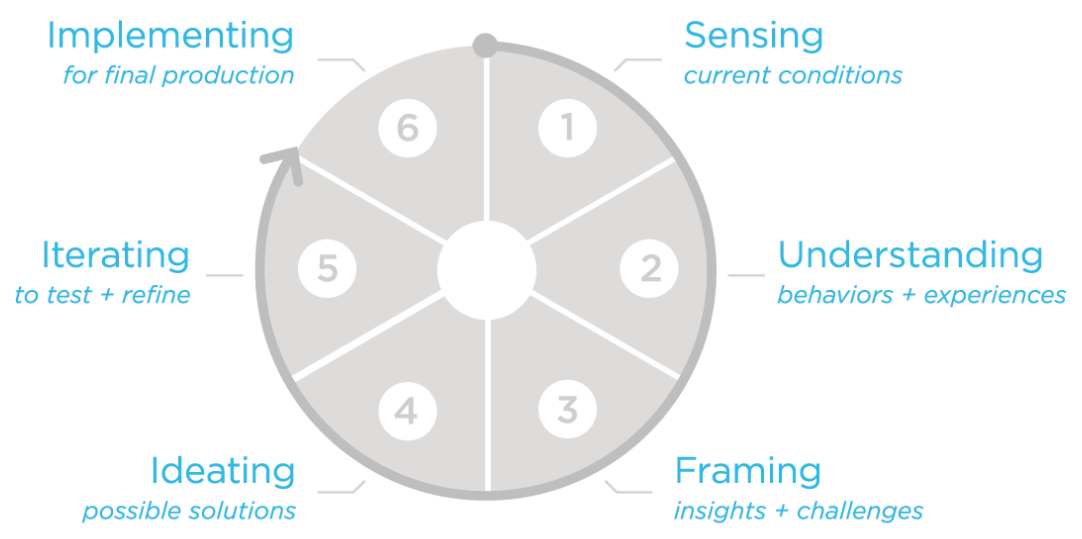

(c) 2015 Collabo Creative LLC. All rights reserved

${ }^{\mathrm{c}}$ According to their website, "MakeTools offers consulting services and education to people and organizations that see the value in using collective forms of creativity to address the environmental, social and cultural challenges we face today."

More information about Maketools can be accessed online at: http:// www. maketools.com/about.html (Accessed November 22, 2016).

\section{0}

Body, J., Terrey, N. \& Tergas, L. "Design Facilitation as an Emerging Design Skill: A Practical Approach,"

in Proceedings of the 8th Design Thinking Research Symposium, 19-20 September 2010, University of Technology, Sydney, Australia, edited by Dorst, K., Stewart, S., Staudinger, I., Paton, B., \& Dong, A. Sydney, Australia: DAB Documents, 2010: pgs. $64-65$. public sector organizations, and the increasingly complex requirements that must be met to effectively engage people within them over time. They state that design facilitation is "... a distinct and emerging role for designers," and they cite Liz Sanders, co-author of the book Convivial Toolbox ${ }^{19}$ and founder of MakeTools, ${ }^{\mathrm{c}}$ to further explain that the role of the designer is now being extended from what was an exclusive, "sole expert" to what is now more of a participatory, inclusive facilitator. ${ }^{20}$

Due to this shift from a "designer-as-expert" mentality to that of "designer-as-facilitator," there is a need to also determine what types of facilitated engagements are most appropriate in particular learning situations. Unger, Nunnally and Willis differentiate between group facilitation, one-on-one facilitation, and one-on-many facilitation, describing different types of interactions and activities for facilitating conversations that can help guide positive transformations. ${ }^{21}$ In the Facilitation: by Design (FxD) workshop series operated by Maggie Breslin and Martin Ratinam on behalf of the AIGA (American Institute of Graphic Arts) at the School of Visual Arts in New York in July of 


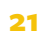

Unger, R. Willis, D. and Nunally, B. Designing the Conversation: Techniques for Successful Facilitation. San Francisco, CA, USA: New Riders/ Peachpit, a division of Pearson Education, 2013, pgs. 19-31.

\section{2}

AIGA. "Facilitation: by Design workshops." AIGA, 16-17 July, 2017. Online. Available at: http://www. aiga.org/facilitation-by-design/ (Accessed 9-14 November, 2016). Material used in this piece was gleaned from dialogue that transpired during the AIGA Facilitation by Design Workshop, led by Bres-

lin, M. and Ratinam, M., hosted by The SVA (School of Visual Arts) Branding Studio, NY, NY, USA, July 16-17, 2015. For further information, contact Mathan Ratinam at Parsons The New School for Design (mathan. ratinamogmail.com) or Maggie Breslin at SVA (maggie.breslinagmail.com).

\section{3}

Body, J., Terrey, N. \& Tergas, L. "Design Facilitation as an Emerging Design Skill: A Practical Approach," in Proceedings of the 8th Design Thinking Research Symposium, 19-20 September 2010, University of Technology, Sydney, Australia, edited by Dorst, K., Stewart, S., Staudinger, I., Paton, B., \& Dong, A. Sydney, Australia: DAB Documents, 2010: pgs. 66-68.
2015, a distinction was made between what they referred to as Workshop Heavy (a workshop as the project in-and-of-itself), and Workshop Light (a workshop that has no particular link to a larger project or to a specific point in the design process). ${ }^{22}$ Breslin and Ratinam further articulated different types of "general workshop categories" that can be linked to different phases of the design process. These included workshops that were titled as follows: "Definition," "Discovery \& Synthesis," “Ideation," "Idea Refinement and Design Execution,” and "Deliverable." Breslin and Ratinam further stressed the point that a designer-as-facilitator must possess, exhibit and master distinct skills and traits in order to successfully facilitate participatory design activities on behalf of diverse groups of people. These include the ability to engage in proactive listening, the ability to moderate and build consensus between competing individuals and groups, and the ability to account for and fairly balance disparate social, cultural, political and economic biases.

The practitioners at ThinkPlace (Body, Terrey and Tergas) and the facilitators of the AIGA FxD workshops (Breslin and Ratinam) also provide rationales for why designers are well-suited for and valued to fulfill roles as facilitators. Body, Terrey and Tergas ${ }^{23}$ contrast design facilitation and generalist facilitation. They describe generalist facilitators as being focused on engaging in a highly structured series of predefined steps with the objective of arriving at a result that is "created, understood and accepted by all participants," and design facilitators as possessing the driving force necessary to iteratively develop and produce a designed outcome, with a heavy emphasis on making, and using a design thinking approach that is heavily influenced by observing specific groups of potential users or audience members as they interact with what has been made. They further articulate the personal qualities and key considerations that designers who fulfill the role of "design facilitator" must exemplify, such as maintaining a strategic, temporally located perspective, a human-centered, empathetic perspective and a perspective informed by the designer's need to make effectively. They then go on to describe techniques for planning and operating different stages of the design process in order to explore, innovate and evaluate. Similarly, embedded within the content delivered by Ratinam and Breslin during the AIGA FxD workshop are four key reasons designers are highly valued as facilitators: 1 . designers are comfortable with ambiguity; 2 . designers play an increasingly key role in planning and orchestrating activities within organizations; 3 . the design profession is necessarily highly collaborative in nature; 4 . designers increasingly infuse the work they do with a human-centered 


\section{4}

AIGA. "Facilitation: by Design workshops." AIGA, 16-17 July, 2017. Online. Available at: http://www. aiga.org/facilitation-by-design/ (Accessed 9-14 November, 2016). Material used in this piece was gleaned from dialogue that transpired during the AIGA Facilitation by Design Workshop, led by Breslin, M. and Ratinam, M., hosted by The SVA (School of Visual Arts) Branding Studio, NY, NY, USA, July 16-17, 2015. For further information, contact Mathan Ratinam at Parsons The New School for Design (mathan. ratinamagmail.com) or Maggie Breslin at SVA (maggie.breslinagmail.com).

Ibid.

\section{6}

AIGA. "Facilitation: by Design workshops." AIGA, 16-17 July, 2017. Online. Available at: http://www. aiga.org/facilitation-by-design/

(Accessed 9-14 November, 2016). Material used in this piece was gleaned from dialogue that transpired during the AIGA Facilitation by Design Workshop, led by Bres-

lin, M. and Ratinam, M., hosted by The SVA (School of Visual Arts) Branding Studio, NY, NY, USA, July 16-17, 2015. For further information, contact Mathan Ratinam at Parsons The New School for Design (mathan. ratinamagmail.com) or Maggie Breslin at SVA (maggie.breslinagmail.com). approach. ${ }^{24}$ During the course of the AIGA FxD workshop, Ratinam and Breslin also stated that effective design facilitators are responsive, attentive, and reflective. ${ }^{25}$ Within the context of people-centered design projects, they must be able to determine what type of planning, preparation, and execution of participatory engagements are most appropriate and when they should occur during whatever iterative steps constitute a given design process.

This discourse helps contextualize and inform a pressing question for visual communication design education: how should the changing role of visual communication designers (from roles that involve more traditional "making" processes those that involve comporting themselves as "design facilitators" of a people-centered design process) affect the curricular goals and learning experiences of visual design education programs geared toward meeting the needs of graduate and undergraduate students? These questions will be addressed throughout the remainder of this piece.

\section{Introducing research facilitation and design facilitation into design education and practice}

\section{Preparing designers to assume roles as facilitators}

The authors are proposing a new framework for distinguishing two emerging roles for those who teach and practice design. This framework is based on knowledge we have constructed and cultivated as we have taught, researched, and practiced people-centered design since 2009. Both require some level of expertise in and around facilitation. We refer to these two roles as Research Facilitation and Design Facilitation.

Research Facilitation is conceptually similar to Breslin and Ratinam's descriptions of "Workshop Light" during their presentation at the AIGA FxD workshop in New York, New York in July of 2015: "a workshop that has no particular tie to a larger project or point in the design process.” ${ }^{26}$ However, we distinguish this role slightly from their description in that the purpose of leveraging facilitation skills during research facilitation is to elicit data-cuminformation through primary research by engaging directly with users or stakeholders. As such, to fulfill a research facilitation role, a designer should be able to satisfy the following goals:

1) Identify and select appropriate participatory design research methods; and 
27

Sanders, E. \& Stappers, P. “Cocreation and the new landscapes of design." CoDesign, 4.1 (2008): pgs. 5-18.

28

Ibid.

29

Almegaard, H. "Problems in Problem Analysis," in Proceedings of the Third International Workshop on Design in Civil and Environmental Engineering, 21-23 August 2014, The Technical University of Denmark, edited by Jensen, L. B., \& Thompson, M.K. Kongens Lyngby, Denmark: The Technical University of Denmark, 2014: pgs. 97-102.
2) Execute whatever participatory design research methods were selected; and

3) Develop and adapt these as needed - all the while accounting for changing user/stakeholder input - as the project evolves iteratively.

A designer who is not engaged in a research facilitation approach to a given project can approach a potential initiative very differently, and not account for user/stakeholder input. She could begin by choosing to identify a problematic situation, contextually and theoretically frame it, and then initiate her research process by formulating, operating, and then gathering, analyzing and assessing data by enacting particular research methods. She could then use this data to support her design decision-making, and ultimately exit that process or project, with no other commitment to or role within it. These types of processes have been practiced by a graphic, industrial, interior, architectural and fashion designers for more than a half a century, and exemplify what has come to be described as "designing for rather than with." ${ }^{27}$ Research facilitation operates quite differently than this more traditional approach, as it strives to meet the three goals articulated earlier in this paragraph.

Design Facilitation can be compared to the concept presented by Breslin and Ratinam as "Workshop Heavy," 28 which describes a situation wherein a "workshop is the project in-and-of-itself." ${ }^{29}$ When fulfilling a role as a design facilitator, the designer's main goals are to: 1) Enable a design process that addresses a specific problematic situation that is broadly inclusive and collaborative; 2) Develop and effectively operate an appropriate participatory design research methodology or set of methods with which to do this; and 3) use the results of this research to affect outcomes to design processes that create appropriate and desirable results, changes and/or actions on behalf of the users and stakeholders who are most affected by the social, economic, technological or political variables at play within the afore-mentioned problematic situation. Designers who plan and implement design facilitation processes tend to need to operate multiple, iterative engagements with users and stakeholders as these processes evolve, and as the users and stakeholders gain knowledge and-often - shift their essential opinions and viewpoints regarding key issues.

Despite the differences in purpose, we propose that effectively fulfilling both types of facilitation roles require that designers construct and cultivate knowledge of and about: 
1) the planning and preparation of research and design facilitation engagements (i.e. workshops, participatory sessions, etc.);

2 several means to effectively plan and manage their interactions with the people who constitute the groups of users and stakeholders with whom they must glean data-cum-information from; and

3) exhibiting and mastering the distinct skills and traits of design facilitators.

\section{A suggestion for a new pedagogical framework for design education}

The authors suggest that the current foundation for visual communication design curricula needs to expand so that it can encompass the need to immerse students in learning experiences wherein they will gain the knowledge and skills necessary to plan, operate, and derive effective results from Research Facilitation and Design Facilitation. Examining the relationship between these two approaches has caused us to conclude that students should initially be exposed to the core experiences and knowledge that inform Research Facilitation, which provides the foundation necessary to then introduce students to Design Facilitation. The rationale for this sequence is supported by the ways that basic, applied and clinical approaches to research can and have effectively informed design processes. ${ }^{30}$ A people-centered approach to engaging in design processes allows these broader approaches to be guided by participatory design research methods. Gaining familiarity with fundamental research frameworks and methods provides the foundation upon which research that accounts for the accrued knowledge and viewpoints of users and stakeholders can be built.

At the Indiana University Herron School of Art and Design, we have coordinated processes for familiarizing graduate students with (first) general approaches to understanding the thinking and methods that frame and guide effective research, and then (second) using these to guide more designerly approaches to knowing ${ }^{31}$ across a two-year program of study. As part of their first year experience, graduate students are exposed to a wide range of research

30

Friedman, K. “Theory construction in design research: criteria: approaches, and methods." Design Studies, 24 (2003): pgs. 507-522.

\section{1}

Cross, N. "Designerly Ways of Knowing." Design Studies, 3.4 (1982): pgs. $221-227$ approaches and methods that can inform design processes. They then draw upon the knowledge and understandings they gain from these first-year experiences to help them effectively formulate and operate participatory research methods during the evolution of specific assigned or student-initiated projects during their second year of study. This experience involves graduate students spending approximately 30 weeks (two North American semesters of study) learning to plan and operate Design Facilitation processes inside the classroom 
and in projects that involve users and stakeholders from communities outside the university. By studying within this structure, these graduate students are provided with ample opportunities to explore, practice, and refine their abilities to facilitate interactions between diverse individuals and groups in iteratively structured, participatory frameworks. To provide viable learning settings within which our students can learn to do this, we have forged and sustained working relationships with area-based, governmental and non-governmental organizations, consultancies and service institutions that we have found to be in need of participatory, facilitated engagements. The activities that our students have been involved in include but have not been limited to strategic planning meetings operated on behalf of various campus committees, charrettes that have incorporated knowledge and insights from community organizations relative to broad and specific problems they are attempting to confront, and "envisioning" workshops aimed at helping groups develop and effectively implement new programs or initiatives. These partners emerge from these interactions with a wide variety of outcomes, including transcriptions and visual syntheses of data-cum-information gleaned and assessed from their interactions with us, and, in some cases, clearly articulated means to plan and operate strategic initiatives.

\section{Addressing challenges to incorporating these approaches into undergraduate and graduate curricula}

The authors have refined and iteratively developed classroom exercises and coursework over the past four years, and continue to encounter significant challenges regarding how to effectively teach students to fulfill roles as research and design facilitators. We have found that immersing students in experience-based learning opportunities is necessary for them to effectively construct the knowledge and grasp the skills necessary to engage in both research and design facilitation. The challenge arises with finding and creating optimal learning environments where the students can feel safe to practice 'new' or 'unfamiliar' skills in 'real' contexts.

In most previous courses students have either been tasked with initiating their own contexts, or the instructor ahead of time set up their community partnerships. Given that these facilitated exercises and activities often times occur outside of class periods the assessment of these engagements then becomes increasingly challenging as well. 
Additionally, a recurring challenging area that appears to be a serious concern for students is in dealing with difficult participants during an actual engagement or session. These kinds of situations can easily be a challenge for even seasoned professional facilitators, therefore it is necessary to determine appropriate ways to enable or simulate high stress environments without 'high stakes,' which is essential for students to practice conflict management and resolution tactics.

The last challenge area that we've encountered deals with teaching and assessing skills (and the knowledge that informs them) that can't necessarily be seen, or are difficult to notice. For example, attunement—or a person's ability to 'read the atmosphere and attitudes in a given room' and then comport herself accordingly as a facilitator - is not only difficult to teach, but is also difficult to assess given the diverse nature of contextual factors that have to be considered to do this with reasonable accuracy. Despite creating exercises and teaching and learning activities that afford students opportunities to develop this skill, the ability to assess a student's attunement becomes evident over a period of time and through noticing specific patterns or lack thereof.

\section{A description of how specific curricular tools can enhance the teaching of research and design facilitation}

The authors have developed a set of tools to address some of the challenges associated with teaching emerging designers to effectively formulate and operate research and design facilitation. These tools were first developed and tested during the authors interactions with specific clients and partners of Collabo Creative, our professional design practice. Prominent among these tools is a strategic framework that can be used to aid the planning and preparation necessary to facilitate collaborative, participatory design sessions. This planning framework has also been incorporated into the design education curriculum at the Herron School of Art and Design.

Based on their experiences planning and operating design facilitation experiences within their classrooms at Herron and in their professional practice at Collabo Creative, the authors contend that preparation and planning are two of the most important factors in being able to successfully engage in Design Facilitation. These ideas have been incorporated into the strategic framework the authors have implemented across the design education curriculum at Herron, which are validated by the tenets of Breslin and Ratinam's workshop. These articulate that, "preparation is key to facilitating a successful workshop" 
Forlizzi, ]. \& Lebbon, C. “From Formalism to Social Significance in Communication Design." Design Issues, 18.4 (2002): pgs. 3-13.

${ }^{d}$ Zoe Strickler articulates several ways for design research to be formulated and conducted to positively benefit visual communication design processes in "Elicitation Methods in Experimental Design Research" (Strickler, z. "Elicitation Methods in Experimental Design Research." Design Issues, 15.2 [1999]: p.27).

An examination of how design research approaches and methods can positively affect research practices in other disciplines through "problem framing" has been articulated by Kees Dorst in his article "Frame Creation and Design in the Expanded Field" (Dorst, K. "Frame Creation and Design in the Expanded Field." She Ji, 1.1 [2015]: pgs. 22-33).

\footnotetext{
${ }^{e}$ The objectives of a session can be widely varied, from gathering groups of doctors, nurses and other hospital personnel together with patients and patients' family members to discuss ways to improve patient's psychological comfort during hospital stays, to gathering groups of educators, educational administrators and students together to discuss ways to improve learning experiences in particular types of classrooms.
}

and "the more preparation you're able to do, the better." We (the authors) have utilized interviews and interactions with our students, our collaborators and others who practice design facilitation to educate ourselves about the value and importance of engaging in broadly informed, comprehensive planning prior to operating design facilitation sessions. We have also found that attending to logistical details - factors such as seating arrangements for participants, the types of drawing and writing materials that are made available for them to use during facilitation sessions, and the orchestration of the scaffolding of information sharing activities - make for more responsive, attentive, and reflective interactions.

Once logistical details are resolved, design facilitators can then advance their planning processes in ways that move them away from their traditional tendencies toward relying predominantly on intuition to guide their interactions with clients, users and audience members. Design facilitators also need to comport themselves in ways that help them build and positively utilize empathetic and sympathetic understandings of and about those who will be affected by the outcomes of design processes in which they are involved. These types of approaches are supported by the scholarship of Forlizzi and Lebbon ${ }^{32}$ (among others), " who have written that, "[designers] also must be concerned about the interaction between the audience, the content of the communication, and the outcomes of the design."

The strategic framework the authors have developed to teach visual communication design students at Herron to effectively formulate and operate design facilitation is comprised of six sections - plus whatever the objectives of a given research or design facilitation session are ${ }^{\mathrm{e}}$ - that feed into and inform each another. These sections are titled People, Time, Environment, Methods, Tools (to make) and Supplies (to take). This structure of this strategic framework is depicted in Figure 2.

The "People" portion of this framework refers to cultivating empathetic and sympathetic understandings of the audience(s) or users who will be affected by the outcomes of a given set of design processes. This requires that design facilitators develop broadly informed and deeply plumbed knowledge about the different types of personalities and roles that individuals and subgroups assume during interaction sessions, and the types of socio-cultural biases and value systems that inform these. Making the most of the Time available to operate a given interactive session is crucial, as design facilitators need to be able to set realistic expectations for what they can accomplish with a given 
POSITION PAPER

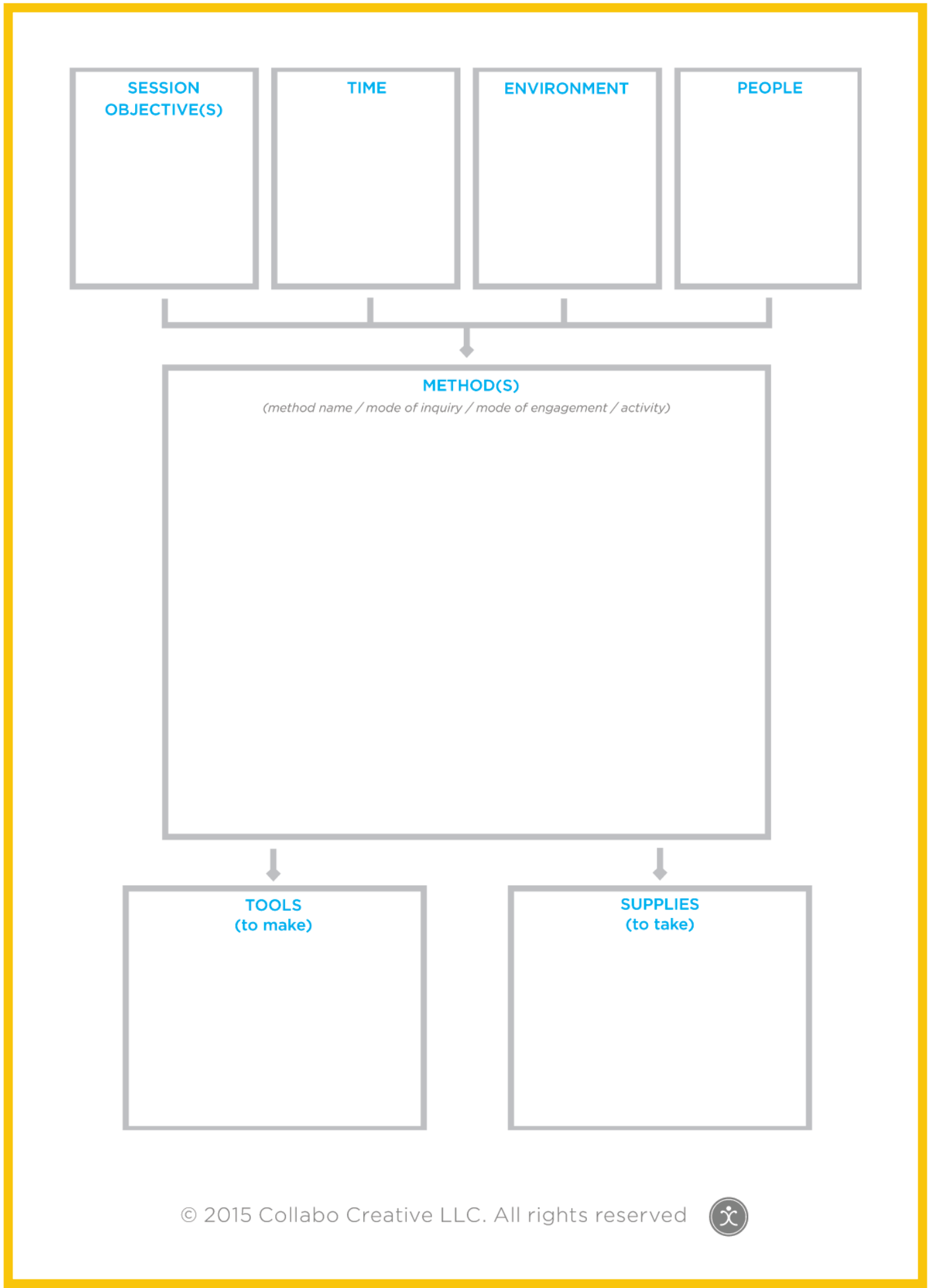

FIGURE 2: The strategic framework depicted here was developed by the authors during a series of interactions with various clients and user and stakeholder groups between 2013 and 2016 at their Indianapolis, Indiana-based design consultancy, Collabo Creative. This framework has also been used to guide learning experiences that introduce design facilitation to visual communication design students at the Herron School of Art and Design. 
group of session participants in a set time frame, and not have the goals of the session be derailed by unexpected exchanges.

The authors have found that it is helpful to think about the Environment within which a data gathering or design facilitation event occurs in terms of its tangible and intangible qualities. These have to be designed, or at least accounted for, in ways that promote rather than inhibit meaningful interactions between participants and researchers or facilitators. Tangible qualities are most often physical: they include the attributes of the space people respond to viscerally, such as how it is lit, how the furniture within it has been arranged to afford physical comfort, and how wall, floor and ceiling surfaces have been treated. Intangible qualities describe the attributes of a space that affect how it performs to affect people's behavior: research and design facilitation participants tend to feel socially uncomfortable in spaces wherein they feel hot or cold, do not have easy access to refreshments or lavatories, or wherein they are made to feel "out of place."

Once information and understandings pertinent and relevant to the sections Time, People and Environment have been gathered, analyzed and documented, the knowledge gained from this is funneled into the section titled Methods. The activities that must be planned for and articulated in this section involve marrying the information and understandings that populate the Time, People and Environment sections with specific methods for gathering, analyzing and assessing data from participants during their interactions with designers and (sometimes) researchers from disciplines outside design. (The authors reference the contents of two books with undergraduate and first-year graduate students to begin to familiarize themselves with a range of design research methods that could potentially be effectively operated within particular time-, people-, and environment-based parameters: Bruce Hanington and Bella Martin's text Universal Methods of Design: 100 Ways to Research Complex Prob-

Hanington, B. \& Martin, B. Universal Methods of Design: 100 Ways to Research Complex Problems, Develop Innovative Ideas, and Design Effective Solutions. Beverly, MA, USA: Rockport Publishers, 2012.

Kumar, V. 101 Design Methods: A Structured Approach for Driving Innovation in Your Organization. Hoboken, NJ, USA: John Wiley \& Sons, Inc., 2013. lems, Develop Innovative Ideas, and Design Effective Solutions ${ }^{33}$ and Vijay Kumar's volume 101 Design Methods: A Structured Approach for Driving Innovation in Your Organization. ${ }^{34}$ ) The Methods section of this strategic framework is also the place within it where whatever specific methods for gathering and processing data that have been chosen for design researchers and facilitators to operate with users, audience members and other stakeholders are formulated into an agenda that can actually be met within the given time, personnel-based and environmental constraints. 
Successfully operating methods for gathering useful and usable data during activities that involve interactions between designers and potential users or project stakeholders requires researchers and facilitators to perform a kind of balancing act. Contributions from particular individuals and groups must be effectively mediated to ensure that specific voices are neither too assertive nor too diminished, documentation must occur within the time allowed, and care must be taken to ensure that the design of a given space promotes rather than inhibits critical exchanges and movement. The final two items in the strategic framework - Tools to make (i.e. worksheets, visuals, etc. to facilitate interactions) and Supplies to take (i.e. post-its, chart paper, markers, food, etc. to aid in documentation and the creation of a collaborative atmosphere) are informed by the knowledge and understandings gleaned from analyzing and assessing the contents of the Time, People, Environment and Methods sections. A well-constructed strategic framework enables a high level of sustained, constructive participation from the greatest possible array of potential users and stakeholders - and the designers they are interacting with - within given specific environmental and temporal constraints.

\section{Areas for Future Research}

As of this writing, the authors are engaged in further research in the area of Design Facilitation, as we continue to apply the knowledge and skills described in this article to new iterations of frameworks and tools that can effectively inform design education and practice. We will continue to develop and test these frameworks and tools in both of these arenas, and assess their relative efficacy in terms of how they might prove to critically affect at least some aspects of 21st century design education. We feel that further scholarly explorations that examine the distinct-yet-interdependent relationships between Research Facilitation and Design Facilitation are also warranted, as are exploring the specific domains of knowledge and skill sets that affect student learning outcomes in and around these areas.

Additionally, we are exploring a pedagogical approach to incorporating Research Facilitation and Design Facilitation into a broader context that involves educating People-Centered Designers. This will include investigations into university-level design education programs that address Design Facilitation in a broad sense, and thus include various aspects of and pertinent to Design Research, Design Management, Design Strategy, and Design Leadership. 
To remain relevant in these new professional realities, a sought-after, and, more to the point, effective designer will need to be able to formulate, conduct, analyze and synthesize the results of research that informs design processes and design decision-making beyond the traditional, cursory client interview and a narrowly framed, shallowly plumbed survey of secondary resources. Rather, the contemporary designer will need to possess the ability to cultivate and effectively utilize meaningful input from the varieties of people who both affect and will be affected by the design processes that guide the development of these projects and their outcomes. Failing to broadly account for the social, economic and technological biases of eventual users and audiences will limit the designers' abilities to create useful, usable and meaningful artifacts, services and experiences with, rather than for, these groups.

\section{References}

+Acumen. "Design kit: Facilitator's guide to introducing human-centered design.” +Acumen. Online. Available at: http://plusacumen.org/courses/ design-kit-facilitators-guide-to-introducing-human-centered-design/ (Accessed 12 October, 2016).

AIGA. "Facilitation: by Design workshops.” AIGA, 16-17 July, 2017. Online. Available at: http://www.aiga.org/facilitation-by-design/ (Accessed 9-14 November, 2016). Material used in this piece was gleaned from dialogue that transpired during the AIGA Facilitation by Design Workshop, led by Breslin, M. and Ratinam, M., developed by Al-Yassini, R., hosted by The SVA (School of Visual Arts) Branding Studio, NY, NY, USA, July 16-17, 2015. For further information, contact Mathan Ratinam at Parsons The New School for Design (mathan.ratinam@gmail.com), Maggie Breslin at SVA (maggie.breslin@gmail.com), or Renna AlYassini (renna@bydesignworkshops.com).

Almegaard, H. "Problems in Problem Analysis," in Proceedings of the Third International Workshop on Design in Civil and Environmental Engineering, 21-23 August 2014, The Technical University of Denmark, edited by Jensen, L. B., \& Thompson, M.K. Kongens Lyngby, Denmark: The Technical University of Denmark, 2014: pgs. 97-102.

Bayazit, N. "Investigating Design: A Review of Forty Years of Design Research.” Design Issues, 20.1 (2004): pgs 16-29. 
Body, J., Terrey, N. \& Tergas, L. "Design Facilitation as an Emerging Design Skill: A Practical Approach,” in Proceedings of the 8th Design Thinking Research Symposium, 19-20 September 2010, University of Technology, Sydney, Australia, edited by Dorst, K., Stewart, S., Staudinger, I., Paton, B., \& Dong, A. Sydney, Australia: DAB Documents, 2010: pgs. 61-70.

Brewster, B., Dowse, E., Hogan, D., Wilkinson, M. \& Woosley, B. “History [of INIFAC]," INIFAC, The International Institute for Facilitation, 28 September, 2006. Online. Available at: http://inifac.org/about-inifac.htm (Accessed 29 November 2016).

Buchanan, R. "Human dignity and human rights: Thoughts on the principles of human-centered design." Design Issues, 17.3 (2001): pgs. 35-39; Norman, D. "Human-centered design considered harmful." Interactions, 12.4 (2005): pgs. 14-19.

Cross, N. "Designerly Ways of Knowing.” Design Studies, 3.4 (1982): pgs. 221-227.

Dorst, K. "Frame Creation and Design in the Expanded Field." She Ji, 1.1 (2015): pgs. 22-33

Dorst, K. \& Lawson, B. Design Expertise. New York, NY, UsA: Architectural Press, (an imprint of Routledge, an imprint of Taylor \& Francis), 2009.

Faste, R., Roth, B. \& Wilde, D.J. “Integrating Creativity into the Mechanical Engineering Curriculum.” In ASME Resource Guide to Innovation in Engineering Design, edited by C. A. Fisher. New York, New York, USA: American Society of Mechanical Engineers, 1993.

Forlizzi, J. \& Lebbon, C. "From Formalism to Social Significance in Communication Design.” Design Issues, 18.4 (2002): pgs. 3-13.

Frascara, J. Design and the Social Sciences: Making Connections. New York, NY, USA: Taylor \& Francis, 2002.

Frascara, J. \& Winkler, D. “Jorge Frascara and Dietmar Winkler on Design Research.” Design Research Quarterly, 3.3 (2008): pgs. 5-6.

Fraser, H. M. A. “Designing Business: New Models for Success.” In Design Thinking: Integrating Innovation, Customer Experience, and Brand Value, edited by T. Lockwood, pgs. 35-46. New York, NY, USA: Allworth Press, 2009.

Friedman, K. “Theory construction in design research: criteria: approaches, and methods." Design Studies, 24 (2003): pgs. 507-522.

Hanington, B. \& Martin, B. Universal Methods of Design: 100 Ways to Research Complex Problems, Develop Innovative Ideas, and Design Effective Solutions. Beverly, MA, USA: Rockport Publishers, 2012. 
Kumar, V. 101 Design Methods: A Structured Approach for Driving Innovation in Your Organization. Hoboken, NJ, USA: John Wiley \& Sons, Inc., 2013. Martin, R. The Design of Business: Why Design Thinking is the Next Competitive Advantage. Cambridge, MA, USA: Harvard Business Press, 2009: pgs. 57-78.

Norman, D. "Why design education must change." Core 77, 10 November 2010. Online. Available at: http://www.core77.com/posts/17993/why-design-education-must-change-17993 (Accessed November 4, 2016). Napier, P. \& Wada, T. “Co-designing for Healthcare: visual designers as researchers and facilitators. Visible Language, 49.1-2 (2015). Online. Available at: http://visiblelanguagejournal.com/issue/161/article/961 (Accessed 2 December 2016).

Sanders, E. \& Stappers, P. “Co-creation and the new landscapes of design.” CoDesign, 4.1 (2008): pgs. 5-18.

Strickler, Z. “Elicitation Methods in Experimental Design Research.” Design Issues, 15.2 (1999): p.27.

Szebeko, D. \& Tan, L. “Co-designing for society.” Australasian Medical Journal, 3.9 (2010): pgs. 580-590.

Unger, R. Willis, D. \& Nunally, B. Designing the Conversation: Techniques for Successful Facilitation. San Francisco, CA, USA: New Riders/Peachpit, a division of Pearson Education, 2013, p. 6.

\section{Biographies}

Pamela Napies is a Co-Founder, Design Strategist \& VP of Operations at Collabo Creative, a strategic design consultancy in Indianapolis, Indiana, U.S.A., and an Assistant Professor of Visual Communication Design at the Herron School of Art and Design, also in Indianapolis, Indiana, U.S.A. She has been teaching across both the graduate and undergraduate curricula there for the past seven years. Through both teaching and practice, Pamela has been invited to give presentations, facilitate workshops, and co-design events nationally and internationally, and has worked with an array of local, regional and national clients on a variety of design research initiatives. She has been an AIGA member since 2002, and was recently appointed as the AIGA Indianapolis Chapter Education Director.pcnapier@iupui.edu 
Tesci Wada is a Co-Founder, Design Strategist \& President of Collabo Creative, a strategic design consultancy in Indianapolis, Indiana, U.S.A., and an and adjunct faculty member in the Visual Communication Design Department at the Herron School of Art and Design, also in Indianapolis, Indiana, U.S.A. Design thinking and research have informed her roles in both design education and practice for most of the past five years. Her work with Collabo has afforded her opportunities to engage in design research-based projects on behalf of a diverse array of organizations, including non-profits, start-ups and fortune 500 companies. Terri's expertise in design is evident in the numerous lectures and presentations she's been invited to give nationally and abroad. Her most recent speaking engagement includes facilitating a people-centered design workshop on behalf of the U.S. Army at the Pentagon in Washington D.C. tawada@iupui.edu 


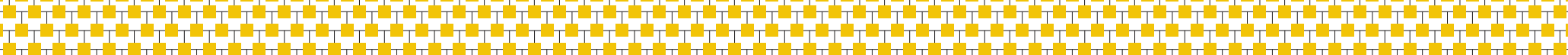
作

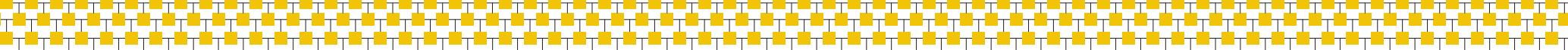

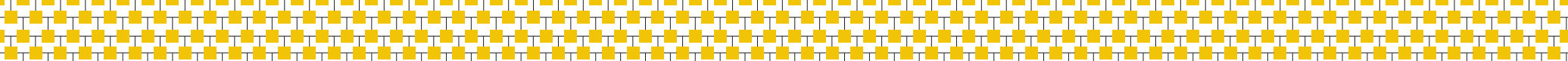

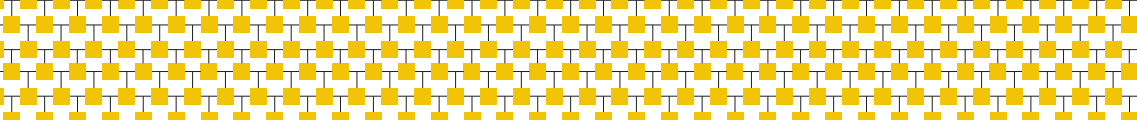

